\title{
BINSEX: UMA PROPOSTA DE BINGO COMO RECURSO DIDÁTICO EM ABORDAGEM CRÍTICA DA EDUCAÇÃO SEXUAL
}

\author{
BINSEX: UNA PROPUESTA DE BINGO COMO RECURSO DIDÁCTICO EN \\ ABORDAJE CRÍTICO DE LA EDUCACIÓN SEXUAL
}

\author{
BINSEX: A BINGO PROPOSAL AS A DIDACTIC RESOURCE IN A CRITICAL \\ APPROACH TO SEXUAL EDUCATION
}

\author{
Ediane da SILVA ${ }^{1}$ \\ Yalin Brizola YARED ${ }^{2}$
}

RESUMO: Apresentamos o bingo como uma proposta de recurso didático-pedagógico em abordagens sobre sexualidade e saúde sexual. Pautado na Declaração dos Direitos Sexuais e no paradigma da educação sexual emancipatória, o jogo objetiva promover o acesso à informação, ao conhecimento científico e à educação sexual esclarecedora. Também visa o estímulo à criação de metodologias diferenciadas que promovam a superação da educação bancária e potencializem a prática pedagógica de docentes de Ciências Biológicas ao abordar temas da educação sexual de forma criativa. De natureza qualitativa, seu planejamento foi orientado a partir da generalidade do Design Based Research (DBR), além dos documentos norteadores: Parâmetros Curriculares Nacionais (1997), Declaração dos Direitos Sexuais (2014) e Proposta Curricular de Santa Catarina (2014). Simulações e avaliações registraram que o Binsex pode incentivar estes docentes e estimular abordagens dialógicas, crítico-reflexivas e lúdicas sobre sexualidade e saúde sexual, potencializando a comunicação, interação e aprendizagem de estudantes.

PALAVRAS-CHAVE: Jogo de bingo. Ensino de biologia. Saúde sexual. Educação sexual emancipatória. Didática em educação sexual.

RESUMEN: Presentamos el bingo como una propuesta de recurso didáctico-pedagógico en abordajes sobre sexualidad y salud mental. Pautado en la Declaración de los Derechos Sexuales y en el paradigma de la educación sexual emancipadora, el juego tiene el objeto de promocionar el acceso a la información, al conocimiento científico y a la educación sexual esclarecedora. También tiene en cuenta estimular la creación de metodologías diferenciadas

${ }^{1}$ Universidade do Sul de Santa Catarina (PPGE/UNISUL), Tubarão - SC - Brasil. Professora de Biologia pela Secretaria de Estado da Educação de Santa Catarina (SED/SC). Mestre em Educação pelo Programa de PósGraduação em Educação. Membro do Grupo de Pesquisa GPECrit - Educação em Ciências e Pensamento Crítico CNPq/UNISUL. ORCID: <http://orcid.org/0000-0002-0885-2350>. E-mail: nane.prof@gmail.com

${ }^{2}$ Universidade do Sul de Santa Catarina (UNISUL), Tubarão - SC - Brasil. Professora do Programa de PósGraduação em Educação - PPGE/Mestrado. Doutora em Educação. Líder do Grupo de Pesquisa GPECrit Educação em Ciências e Pensamento Crítico CNPq/UNISUL. Membro do Grupo de Pesquisa EDUSEX Formação de Educadores e Educação Sexual CNPq/UDESC. ORCID: <http://orcid.org/0000-0001-8773-9358>. E-mail: yalinbio@gmail.com

RIAEE - Revista Ibero-Americana de Estudos em Educação, Araraquara, v. 14, n. esp. 2, p. 1580-1600, jul., 2019. E-ISSN: $1982-5587$. DOI: $10.21723 /$ riaee.v14iesp.2.12617 
que promocionan la superación de la educación bancaria y potencializan la práctica pedagógica de docentes de Ciencias Biológicas al abordar temas de la educación sexual de forma creativa. De naturaleza cualitativa, su planeamiento fue orientado a partir de la generalidad del Design Based Research (DBR), además de los documentos orientadores: Parámetros Curriculares Nacionales (1997), Declaración de los Derechos Sexuales (2014) y Propuesta Curricular de Santa Catarina (2014). Simulaciones y evaluaciones registran que el Binsex puede incentivar estos docentes a estimular abordajes dialógicas, crítico-reflexivas y lúdicas sobre sexualidad y salud sexual, potencializando la comunicación, interacción y aprendizaje de estudiantes.

PALABRAS CLAVE: Juego de bingo. Enseñanza de biología. Salud sexual. Educación sexual emancipadora. Didáctica en educación sexual.

ABSTRACT: We present bingo as a proposal of didactic-pedagogical resource in approaches on sexuality and sexual health. Based on the Declaration of Sexual Rights and the paradigm of emancipatory sexual education, the game aims to promote access to information, scientific knowledge and enlightening sex education. It also aims to stimulate the creation of differentiated methodologies that promote the overcoming of banking education and potentiate the pedagogical practice of Biological Sciences teachers when approaching themes of sex education in a creative way. From a qualitative perspective, his planning was based on Design General Research (DBR), in addition to the guiding documents: National Curricular Parameters (1997), Declaration of Sexual Rights (2014) and Curricular Proposal of Santa Catarina (2014). Simulations and evaluations have shown that Binsex can encourage these teachers and stimulate dialogic, critical-reflexive and ludic approaches to sexuality and sexual health, enhancing communication, interaction and student learning.

KEYWORDS: Bingo game. Biology teaching. Sexual health. Emancipatory sexual education. Didactics in sexual education.

\section{Introdução}

Apresentamos no presente texto a trajetória iniciada na produção de um jogo de bingo como proposta didático-pedagógica para o ensino de Biologia referente a temática da Educação Sexual. Esse movimento, além de ser pautado na Declaração dos Direitos Sexuais (WAS, 2014), entendida como Direitos Humanos universais e fundamentais, é resultado das reflexões da primeira autora sob orientação da segunda autora, do processo vivido no relacionamento de orientação entre mestranda e orientadora. A proposta do referido jogo surgiu a partir da vivência da primeira autora como docente efetiva da rede pública estadual de ensino de Santa Catarina na disciplina de Biologia e mestranda de um Programa de Pós-Graduação em Educação (PPGE) de uma universidade comunitária do Sul do Brasil, na Linha de Pesquisa Educação em Ciências. 
A vivência no curso de Mestrado em Educação e no contexto do Grupo de Pesquisa GPECrit Educação em Ciências e Pensamento Crítico, compreendeu intensas problematizações sobre práticas didático-pedagógicas para o ensino de Ciências e Biologia em interface com as teorias da educação sexual emancipatória e as teorias do pensamento crítico. Uma das finalidades desse processo foi refletir criticamente sobre os desafios atuais das abordagens em educação sexual nas escolas e desenvolver possíveis estratégias metodológicas lúdicas sobre a temática que possam ser utilizadas por docentes, especificamente os de Ciências e Biologia.

De acordo com os Parâmetros Curriculares Nacionais (BRASIL, 1997), o tópico "Ser Humano e Saúde" está entre os eixos temáticos propostos à área de Ciências Biológicas, portanto, conhecimentos com importância social, significado e relevância científicotecnológica para os/as estudantes. Nesse mesmo documento a educação sexual também compreende elemento importante como tema transversal ${ }^{3}$. No estado de Santa Catarina dispomos de uma proposta curricular específica, atualizada em 2014, que apresenta a diversidade e a formação integral dos sujeitos como princípios formativos (SANTA CATARINA, 2014). Além disto, a nível de tratados e convenções internacionais, a Declaração dos Direitos Sexuais traz explicitamente que todas as pessoas devem ter acesso à informação científica e à educação sexual esclarecedora (WAS, 2014).

Por que o foco nos/as professores/as de Ciências e Biologia? A própria cultura do ambiente escolar, em grande parte das vezes, entende a educação sexual como de obrigação de docentes da área de Ciências Biológicas, inclusive por apresentarem explicitamente assuntos que envolvem a temática em seus livros didáticos. É o que ficou registrado na pesquisa de Yared (2011) ao confirmar que os/as docentes dessa área ainda são vistos como os "responsáveis", ademais, os "autorizados" para trabalhar o tema com os/as estudantes nas escolas. Mas Yared (2011) também registrou que os/as docentes demonstram insegurança e medo, além de acreditarem que não passam credibilidade em suas abordagens. Além disso, também vivenciam constantemente a (re)produção de mitos, crenças e tabus acriticamente reproduzidos por meio do currículo oculto ${ }^{4}$, o que contribui para a perpetuação inconsciente de paradigmas repressores,

3 De acordo com os PCN's, os temas transversais são temas a serem trabalhados por professores/as de todas as áreas do conhecimento e que no caso da educação sexual, busca a promoção da saúde e bem-estar de crianças, adolescentes e jovens. De acordo com Santos e Bruns (2000) normalmente é de responsabilidade do/a professor/a de Ciências ou de Biologia o desenvolvimento dos aspectos biológicos dos sujeitos, o que exclui, em muitos casos, os aspectos socioculturais e simbólicos da sexualidade. Logo, um tema transversal é um "tema [que] deverá ser tratado por quaisquer professores de todas as áreas dentro da grade curricular ou em horários extraclasse, desde que se sintam mobilizados para tal", (SANTOS e BRUNS 2000, p. 30).

${ }^{4}$ Santomé (1995, p. 201) explica que o currículo oculto diz respeito aos conhecimentos, destrezas, atitudes e valores que se adquirem mediante a participação em processos de ensino e aprendizagem e, em geral, em todas as RIAEE - Revista Ibero-Americana de Estudos em Educação, Araraquara, v. 14, n. esp. 2, p. 1580-1600, jul., 2019. E-ISSN: $1982-5587$. 
reducionistas e patologizantes de sexualidade, especialmente a vertente médico-biológica (NUNES, 1996).

Somando-se a este cenário, vivemos atualmente no Brasil em pleno século XXI, perdas de direitos humanos e retrocessos sociais que refletem diretamente no campo da Educação e da Educação Sexual - materializado especificamente pelo Projeto de Lei n ${ }^{\circ}$. 867/2105 que se refere ao "Escola sem partido". Propostas como estas surgem a partir de grupos conservadores e religiosos com a pretensão de combater "ideologias nas escolas" em prol da "neutralização escolar" (AÇÃO EDUCATIVA, 2016). Professores e professoras de diversas partes do país, tanto da educação básica como superior, pública, privada ou comunitária, estão sendo intimidados e/ou processados judicialmente por "doutrinação ideológica" - o que se intensifica quando o trabalho pedagógico compreende as temáticas de sexualidade e gênero.

Conversar sobre sexualidade e educação sexual de maneira responsável e científica sempre apresentou desafios, mas atualmente, como afirma Mattos et al. (2017, p. 94)

Na prática, pretende-se inviabilizar e mesmo criminalizar todas as iniciativas educativas propostas por professoras e professores que abordem temas como desigualdades de gênero, diversidade sexual (na escola e na sociedade), o combate ao preconceito, ao sexismo e à LGBTfobia. Além disso, materiais didáticos e paradidáticos com abordagem crítica e reflexiva sobre esses temas têm sido alvos de ataques pelos partidários do movimento. Seus defensores vêm afirmando que esse tipo de material e discussão "doutrinam" estudantes (grifo dos autores).

Contraditoriamente, temos uma realidade brasileira extremamente preocupante: maior índice de gravidez na América Latina; aumento no contágio de IST/Aids principalmente em jovens; o alto índice de abuso sexual infantil; e o alto índice de feminicídio e de violência e assassinato à população $\mathrm{LGBT}^{5}$. Portanto, como não problematizarmos sexualidade, relações de gênero e educação sexual em um viés emancipatório, crítico e que promova a igualdade, equidade e o respeito às diferenças?

interações que se dão no dia-a-dia das aulas e escolas. Estas aquisições, no entanto, nunca chegam a explicitar-se como metas educativas e de forma intencional. Assim, "aprendem-se, através do currículo oculto, atitudes e valores próprios de outras esferas sociais, como, por exemplo, aqueles ligados à nacionalidade. Mais recentemente, nas análises que consideram também as dimensões do gênero, da sexualidade ou da raça, aprende-se no currículo oculto, como ser homem ou mulher, como ser heterossexual ou homossexual, bem como a identificação com uma determinada raça ou etnia. (...) O currículo oculto ensina, ainda, através de rituais, regras, regulamentos, normas”, (SILVA, 2005, p. 79).

5 "Originalmente a sigla significa Lésbicas, Gays, Bissexuais e Travestis. Vista como uma forma reduzida da chamada comunidade homossexual, o "T" pode ser entendido como uma referência aos sujeitos "trans" (travestis, transexuais e transgêneros). Diferentes autores, comumente, usam a sigla LGBTTTI (que, além de visibilizar todos os sujeitos trans, o "I" refere-se aos intersexuais)" (SANTA CATARINA, 2014, p. 59).

RIAEE - Revista Ibero-Americana de Estudos em Educação, Araraquara, v. 14, n. esp. 2, p. 1580-1600, jul., 2019. E-ISSN: $1982-5587$. 
O bingo Binsex, então, surge nesse contexto: da importância do enfrentamento contra a censura desta temática e da necessidade de incentivar e fortalecer as discussões críticareflexivas sobre sexualidade e educação sexual, destacando sua relevância na vida de cada cidadão e cidadã. $O$ jogo objetiva, portanto, promover o acesso à informação, ao conhecimento científico e à educação sexual esclarecedora; bem como estimular docentes de Ciências Biológicas a abordar temáticas sobre sexualidade e saúde sexual a partir de metodologias diferenciadas que potencializem práticas didático-pedagógicas mais lúdicas, criativas, críticas e ativas.

\section{O bingo como um recurso pedagógico: fundamentação teórica}

Partimos do pressuposto de que a dimensão sexualidade encontra-se na base das expressões humanas, constituinte da condição ontológica (NUNES, 1996; MELO; POCOVI, 2008; YARED, 2016). Nessa ótica, compreendemos que o ser humano não "tem" sexualidade, ele "é” sexualidade (CABRAL, 1995). De acordo com a Organização Mundial da Saúde (OMS, 1975), a sexualidade é

Parte integral da personalidade de todo ser humano, é construída por meio da interação entre os sujeitos e as estruturas sociais. A sexualidade é uma energia que nos motiva a procurar amor, contato, ternura e intimidade, que se integra no modo como nos sentimos, movemos, tocamos e somos tocados, é ser-se sensual e ao mesmo tempo sexual; ela influencia pensamentos, sentimentos, ações e interações e, por isso, influencia também a nossa saúde física e mental.

Assim, afirmamos que a sexualidade "é uma dimensão indissociável do fato de sermos humanos" (MELO et al., 2011, p. 23), em todos os momentos de nossas vidas, em qualquer ambiente, inclusive nos ambientes escolares. Consequentemente, os seres humanos não podem apresentar sua sexualidade como algo isolado, externo de si, algo deixado de fora de seus corpos, porque "os corpos são as pessoas, pessoas estas sempre sexuadas”, (MELO, 2004, p. 52). Então, a sexualidade

[...] é uma parte integral da personalidade de todo ser humano. Seu desenvolvimento pleno depende da satisfação de necessidades humanas básicas como desejo de contato, intimidade, expressão emocional, prazer, ternura e amor. A sexualidade é construída através da interação entre o indivíduo e as estruturas sociais. O desenvolvimento pleno da sexualidade é essencial para o bem-estar individual, interpessoal e social (MELO; POCOVI, 2008, p. 44). 
E a sexualidade humana e a saúde sexual, expressos na Declaração dos Direitos Sexuais (WAS, 2014), representam direitos universais. "Os direitos sexuais protegem os direitos de todas as pessoas na plena realização e expressão de sua sexualidade, usufruindo de sua saúde sexual, desde que respeitados os direitos do próximo", (WAS, 2014, p. 02). A referida declaração apresenta 16 itens que constituem os direitos sexuais e, especificamente, os itens 9 e 10 tratam do direito à informação, à educação e à educação sexual esclarecedora:

9. O direito à informação: todos devem ter acesso à informação cientificamente precisa e esclarecedora sobre sexualidade, saúde sexual, e direitos sexuais através de diversas fontes. Tal informação não deve ser arbitrariamente censurada, retida ou intencionalmente deturpada.

10. O direito à educação e o direito à educação sexual esclarecedora: todos têm o direito à educação e a uma educação sexual esclarecedora. Educação sexual esclarecedora deve ser adequada à idade, cientificamente acurada, culturalmente idônea, baseada nos direitos humanos, na equidade de gêneros e ter uma abordagem positiva quanto à sexualidade e o prazer (WAS, 2014, p. 02).

Destarte, ressaltamos a importância e o direito de se trabalhar a sexualidade, relações de gênero e educação sexual nos ambientes escolares. Porém, ao contrário de práticas pedagógicas domesticadoras, antidialógicas e repressoras, que não problematizam explícita e criticamente o tema, torna-se necessário o desenvolvimento de estratégias didáticas diferenciadas, inovadoras, capazes de sensibilização e reflexão, que visem a partilha de um saber efetivo, dinâmico e criativo, pois a “educação sexual não é uma mera questão técnica, mas, sim, uma questão social, estrutural, histórica" (NUNES, 2005, p. 14).

Nessa perspectiva, nossas discussões são fundamentadas no paradigma de sexualidade cunhada por Nunes (1996), denominado vertente pedagógica de educação sexual Dialética e Política, que está direcionada para a emancipação dos sujeitos, busca a valorização dessa importante dimensão humana e "a consciência crítica da complexidade desse processo que é dinâmico, ou seja, está sempre em movimento na busca da superação da contradição e alienação" (YARED, 2016, pg. 84).

A sexualidade emancipatória é aquela que nos dá condições de compreender a dinamicidade, a complexidade, a riqueza única da sexualidade humana. Nesta direção o conceito emancipatório busca superar um conceito de alienação; entendemos que as abordagens delineadas anteriormente, presentes hoje em muitas propostas de educação sexual, poderiam todos ser circunscritos de conceito de alienação, próprio do pensamento marxista (NUNES, 1996, p. 227). 
Nesse sentido, é preciso superar a alienação e elucidar para a emancipação também por meio de docentes que acreditem em processos emancipatórios em educação sexual, que estimulem um pensar crítico-reflexivo, além de fomentar a autorreflexão, autoconfiança, a autodeterminação (YARED, 2016).

Nessa perspectiva, compreendemos que o pensamento crítico se apresenta como uma "forma superior de pensamento, integrando capacidades, disposições, conhecimentos e normas, aplicável no quotidiano (seja pessoal, académico, laboral ou social) para pensar bem, encontrar explicações, tomar decisões e solucionar desafios", (FRANCO; VIEIRA; SAIZ, 2017, p. 12, grifo dos autores). Fundamentadas em Tenreiro-Vieira e Vieira (2000) e Vieira e TenreiroVieira (2014), compreendemos que pensar criticamente representa o desenvolvimento de um pensar mais elaborado e reflexivo, sendo o alicerce no enfrentamento à situações problemas do cotidiano - neste caso, no desafio que docentes de Ciências Biológicas enfrentam no seu cotidiano diante da temática da sexualidade e saúde sexual. Segundo Ennis (2011, p. 01), o pensamento crítico "um pensamento razoável e reflexivo focado em decidir em que acreditar ou fazer". É um pensamento que envolve, de acordo com Tenreiro-Vieira (2014, p. 31), “tanto disposições, que dizem respeito aos aspectos mais afetivos", como as habilidades, "que se reportam a aspectos mais cognitivos." Logo, é uma maneira de pensar racional e reflexivo, com amplo papel desempenhado na vida dos sujeitos, "uma vez que todo o comportamento depende daquilo em que se acredita, toda ação humana depende, de algum modo, daquilo que se decide fazer" (VIEIRA; TENREIRO-VIEIRA, 2005, p. 90).

Promover um pensar crítico inclui em aprimorar as capacidades de questionar, de refletir, de contextualizar as diversas situações da vida cotidiana, especialmente nos dias atuais, onde vivenciamos o acesso a diversas informações e precisamos da capacidade de relacioná-las ao contexto escolar. Contudo, pensar criticamente não é algo inato ao humano, ou seja, "não é algo natural"; ao contrário, é um processo que pode - e deve - ser "incitado pelo ensino e carece de aperfeiçoamento ao longo do tempo de escolaridade" (FRANCO; VIEIRA; SAIZ, 2017, p. $13)$.

Entretanto, compreendemos que não é possível cidadãos e cidadãs pensarem criticamente sem acesso à informação correta. A informação correta é base fundamental para que seres humanos possam exercitar seu pensamento crítico. Logo, não podemos ser sujeitos crítico-reflexivos em relação à área da sexualidade humana baseados em equívocos, informações errôneas, crenças, mitos e tabus. Torna-se necessário o efetivo acesso crítico ao seu conhecimento científico e problematização com questões do cotidiano. Portanto, nos RIAEE - Revista Ibero-Americana de Estudos em Educação, Araraquara, v. 14, n. esp. 2, p. 1580-1600, jul., 2019. E-ISSN: $1982-5587$. DOI: $10.21723 /$ riaee.v14iesp.2.12617 
questionamos: qual a efetividade de um jogo de bingo como uma proposta de recurso didáticopedagógico com vistas a uma reflexão crítica sobre sexualidade e saúde sexual?

De acordo com os PCN, a "participação em jogos de grupo também representa uma conquista cognitiva, emocional, moral e social [...] e um estímulo para o desenvolvimento do seu raciocínio lógico" (BRASIL, 1997, p. 36). Nesse sentido, proporcionar ambientes que estimulem a criatividade, a curiosidade, a cooperação, bem como, o lúdico, são aspectos almejados pelos jogos, visto que

[...] um aspecto relevante nos jogos é o desafio genuíno que eles provocam no aluno, que gera interesse e prazer. Por isso, é importante que os jogos façam parte da cultura escolar, cabendo ao professor analisar e avaliar a potencialidade educativa dos diferentes jogos e o aspecto curricular que se deseja desenvolver" (BRASIL, 1997, p. 36).

E o processo de ensino-aprendizagem pode ser mais efetivo a partir do lúdico e da tentativa de rompimento com a educação bancária (FREIRE, 2005). Ou seja, metodologias que promovam práticas pedagógicas diferenciadas, em que não se "depositem" conteúdos, mas promovam um processo mais participativo, despertando a curiosidade e a reflexividade sobre situações do cotidiano - escolar e da vida. Ainda, "os jogos constituem uma forma interessante de propor problemas, pois permitem que estes sejam apresentados de modo atrativo e favorecem a criatividade na elaboração de estratégias de resolução e busca de soluções" (BRASIL, 1997, p. 46).

Compreendemos que o desenvolvimento de jogos também pode estimular as relações interpessoais e o diálogo, o que pode colaborar com as interações sociais. E, intencional e conscientemente, a aprendizagem por meio de jogos pode também promover capacidades como identificar, analisar, avaliar, tirar conclusões e questionar determinadas informações que temos acesso - que vem ao encontro de um pensamento mais crítico e reflexivo, tanto de docentes como de discentes. Assim, desenvolver estratégias de ensino-aprendizagem específicas para a problematização da sexualidade pautadas num viés emancipatório torna-se uma necessidade, pois pode representar um espaço específico de educação sexual que pode envolver atividades corporais, dramatização e "ajudar a concretizar noções, como percepção, apropriação do próprio corpo, autodomínio e autocuidado" (BRASIL, 1997, p. 334).

Almejamos, portanto, a partir da proposta do jogo Binsex, incentivar e mobilizar docentes, especialmente de Ciências Biológicas, a trabalhar as temáticas da sexualidade e saúde sexual conscientes e criticamente, superando abordagens bancárias, funestas e envolvendo 
didática e dialogicamente os/as estudantes. Desta forma nos questionamos: é possível, a partir de um jogo de bingo, promover o acesso à informação e conhecimento científico sobre sexualidade e saúde sexual de maneira participativa, reflexiva e lúdica?

\section{O bingo como um recurso metodológico: a busca por estratégias inovadoras em educação sexual para o ensino de Ciências e Biologia}

O bingo Binsex busca promover um espaço dinâmico em sala de aula, voltado para as reflexões sobre conceitos e termos presentes no livro didático de Biologia ligados à sexualidade e saúde sexual pautado no paradigma emancipatório. Visa um ambiente lúdico, em que docente e discentes possam interagir de forma criativa e crítico-reflexiva. O movimento de sua elaboração compreendeu diversas situações, descritas a seguir.

No ano de 2017, a vivência da primeira autora se constituiu em três momentos importantes que influenciaram significativamente na construção do jogo: a) a realização do estágio de docência na disciplina intitulada "Prática no Ensino de Ciências e Biologia", no curso de Licenciatura em Ciências Biológicas, em 2017/01; b) a participação em um curso de extensão sobre "Educação Sexual Emancipatória", ofertado na própria universidade ao curso de Licenciatura em Ciências Biológicas, num total de 28h, em 2017/02; c) cursar no mestrado a disciplina de "Pensamento Crítico na Educação em Ciências" em 2017/02, onde foi solicitada a criação de uma proposta de atividade inovadora para o ensino de Ciências e/ou Biologia e que visasse instigar a promoção do pensamento crítico. Desta forma, a primeira autora escolheu criar a atividade em interface com a educação sexual emancipatória, originando, assim, o referido jogo de bingo intitulado de "Binsex". Ressaltamos que o Binsex foi apresentado no IX Colóquio do Grupo de Pesquisa EDUSEX - Formação de Educadores e Educação Sexual $\mathrm{CNPq} / \mathrm{UDESC}^{6}$.

Este estudo trata-se de uma pesquisa qualitativa e orientou seu planejamento a partir da generalidade do Design Based Research (DBR), que, ao contrário das pesquisas tradicionais, envolve "estudos em pequena e média escala de tempo" (KNEUBIL e PIETROCOLA, 2017, p. 01). São estudos que normalmente se propõem a analisar impactos de proposta inovadoras,

${ }^{6}$ Evento realizado em Florianópolis pela Universidade do Estado de Santa Catarina/UDESC, em dezembro de 2017, sob temática "Saberes e fazeres no campo da Educação e Sexualidade: Contribuições para processos educativos intencionais com vistas à emancipação humana”. O Binsex foi apresentado na mesa redonda: "Conversando sobre Inovações metodológicas nas aulas do século XXI como subsídios à temática da educação sexual" - contribuições das Ciências Biológicas.

RIAEE - Revista Ibero-Americana de Estudos em Educação, Araraquara, v. 14, n. esp. 2, p. 1580-1600, jul., 2019. E-ISSN: $1982-5587$. 
sejam "de conteúdo, metodologia, ou organização das atividades de ensino-aprendizagem" (idem, p. 02). Nesse sentido, a DBR representa pesquisas e estudos que "combinam empiricamente a pesquisa educacional teórica com ambientes de aprendizagem" e consistem na "implementação de uma inovação educacional em contextos escolares reais" (idem, p. 02).

O processo inicial de confecção do Binsex ocorreu, efetivamente, no segundo semestre do ano de 2017, durante a disciplina do mestrado e a vivência no curso de extensão - o que proporcionou um espaço privilegiado para a realização de simulações iniciais do jogo, com autorização e apoio dos cursistas presentes. Como ponto de partida, o Binsex foi construído com base no livro didático da disciplina de Biologia do Ensino Médio, referente aos conteúdos de "anatomia e fisiologia do sistema reprodutor masculino e feminino", "infecções sexualmente transmissíveis (ISTs)" e "método contraceptivos". A seleção do tema, conforme justificado na introdução, visava a melhoria da qualidade do processo de ensino-aprendizagem sobre temáticas que envolvem a sexualidade e saúde sexual, pois atualmente ainda é muito comum serem utilizados apenas "palestras" como recurso didático nessas abordagens - inclusive por profissionais externos à escola - o que promove um ambiente com pouco ou nenhum diálogo e uma postura passiva dos/as estudantes.

Refletir sobre inovação metodológica para o ensino de Ciências e Biologia representa um desafio, especialmente em educação sexual. Fundamentadas em Garcia e Bizzo (2010), compreendemos a inovação como "um conjunto de intervenções, decisões com certo grau de intencionalidade e sistematização, que visam a transformar as atitudes, ideias, culturas, conteúdos, modelos e práticas pedagógicas” (p. 19). Nesse sentido,

[...] existem três possibilidades de inovação no ensino: aquelas relacionadas à utilização de novos materiais, currículos e tecnologias; o uso das novas abordagens de ensino, estratégias e atividades; e a possibilidade de mudanças nas crenças e pressupostos que são subjacentes às práticas pedagógicas. (FULLAN, 2001, p. 39 apud GARCIA; BIZZO, 2010, p. 20)

E esse entendimento vem ao encontro de Kneubil e Petrocola (2017), quando afirmam que a inovação de natureza didática é "uma inovação em relação à forma e a à maneira como se ensina e aprende determinado conteúdo curricular", (p. 08). Inclusive, destacamos que durante o desenvolvimento inicial da proposta do Binsex, foi realizada uma busca sistemática em bases de dados na expectativa de encontrar alguma publicação semelhante - que não foi encontrada. 
Considerando então o desafio da temática e o amplo uso de palestras como estratégia didática, compreendemos que a proposta do Binsex pode representar uma alternativa metodológica em educação sexual para contribuir em ações pedagógicas que visem a superação da educação bancária e que promovam intervenções pautadas na perspectiva emancipatória de sujeitos, além do entendimento consciente dos Direitos Sexuais enquanto Direitos Humanos fundamentais e universais. E destacamos que o movimento de criação dessa estratégia ficou significativamente enriquecido por dois motivos principais: a primeira autora é professora de Biologia na rede pública estadual; a problemática surge em sua vivência no ambiente escolar, portanto, com sentidos e significados da vida real.

Os movimentos de criação compreenderam a busca na internet por imagens alternativas de cartelas que serviram como modelo para inspirar a confecção das cartelas atuais (Anexo 1). A partir dessa busca foram repensadas a (re)organização das cartelas do Binsex, como por exemplo, a disposição de símbolos e/ou imagens, a quantidade de número de colunas e linhas, o número de séries e a quantidade de palavras (ao invés de números, como um bingo tradicional) - movimento este que foi reavaliado a cada simulação em que o Binsex foi submetido.

O Binsex é composto atualmente por dois tipos de cartelas: uma cartela mestre e quatro cartelas série. A cartela mestre apresenta preenchimento com símbolos e palavras, sendo: cinco (05) símbolos que ocupam o free space e quinze (15) palavras, totalizando 20 células - sendo que esta é a cartela que comanda as "rodadas" do jogo. As cartelas série também são compostas por 20 células, porém apresentam apenas símbolos que ocupam o free space e espaços em branco, para preenchimento pelos/as participantes/estudantes ao longo das "rodadas". Ao total, foram confeccionadas trinta e cinco (35) cartelas mestre diferentes. O Binsex também acompanha uma lista de questões numerada de 01 a 39 (Anexo 2), que fica de posse do/a docente, em que cada número está relacionado a uma questão e a resposta refere-se a uma palavra da cartela mestra - ou seja, palavras retiradas do livro didático de Biologia.

\section{O bingo Binsex: implementação e avaliação}

Especificamente sobre a implementação, o Binsex teve cinco (05) simulações durante um ano letivo, que compreendeu os semestres 2017/02 e 2018/01, quais foram: a) duas simulações com os/as participantes do referido curso de extensão em 2017/02, visto que o curso também era desenvolvido com metodologias ativas; b) duas simulações com estudantes do $2^{\circ} \mathrm{e}$ 
$3^{\circ}$ ano do Ensino Médio de uma escola pública estadual de Santa Catarina, durante a disciplina de Biologia ministrada pela primeira autora em 2017/02; c) uma simulação com estudantes de graduação, durante um Workshop promovido pela primeira autora na disciplina de "Prática no Ensino de Ciências e Biologia" sobre "Alternativas inovadoras didático-pedagógicas para potencializar a prática docente em Ciências e Biologia”, em 2018/01. As simulações realizadas foram extremamente relevantes para aperfeiçoar o jogo, processo este longo, porém criativo, de construção, desconstrução e aperfeiçoamento da lista de questões e das cartelas coletivamente, inclusive em séries - modelo atual. Durante as simulações, todos/as os/as participantes avaliaram e contribuíram com sugestões para o melhoramento do jogo.

Como no jogo de bingo tradicional, o Binsex consiste no preenchimento da 'cartela cheia' ou parcial, podendo ser de duas formas: preenchimento por coluna vertical correspondente à letra escolhida (B-I-N-G ou O) ou preenchimento aleatório de cinco (05) palavras, independente da letra/coluna, em qualquer célula da cartela. Essa proposta de bingo pode proporcionar várias "rodadas", dependendo do(s) tipo(s) de preenchimento(s) em cada série. A operacionalização e o tipo de preenchimento ao longo das rodadas são de comando do/a docente. Consequentemente, o tempo de duração do jogo está diretamente relacionado ao tipo de preenchimento das células. Para jogar, os/as participantes/estudantes receberam uma cartela do Binsex em uma folha de papel ofício composta por uma cartela mestre e quatro cartelas série (Anexo 1), além de grãos de arroz/feijão/milho para marcação. Em seguida, em posse de um aparelho de bingo - podendo este ser de brinquedo ou profissional - o/a docente começará a rodar o globo e fazer o sorteio dos números. Conforme quadro da lista de questões citado anteriormente, o número de bolas deverá ser igual ao número de questões, sendo extraídas as bolas extras contidas no jogo original de bingo.

A partir das simulações realizadas, registramos que a opção "cartela cheia" necessita de maior tempo de aula/duração, ao contrário do preenchimento de algumas "coluna/aleatório". Identificamos também que desenvolver as cartelas série com todo o preenchimento da "coluna/aleatório" e a cartela mestre com o preenchimento "cartela cheia" pode resultar em um tempo de 35 minutos de aula. E em cada "rodada", o/a participante/estudante vencedor/a recebeu um brinde surpresa - que, em nosso caso, foi utilizada uma caixa de bombons, em que cada estudante vencedor/a, em cada rodada, escolhia um bombom. Em caso de empate, conforme jogo original, foi sorteada a "pedra maior" ou "pedra menor", dependendo da coordenação do/a docente. 
Durante a operacionalização do jogo, o/a estudante deverá estar atento/a às questões realizadas pelo/a professor/a e, então, começar a pontuar sua/as cartela/as. Registramos que o processo de ensino-aprendizagem se potencializou a partir da interação entre docente e discentes, em que ambos podem ser sujeitos no processo. Ou seja, por meio de um ambiente participativo - visando a superação de uma postura passiva de ouvinte numa aula expositiva tradicional - a relação entre docente e discentes foi efetivamente mediada pelo conhecimento científico e o acesso à informação. Inclusive, notamos que no momento do jogo todo/as os/as estudantes participaram efetivamente e ficaram focados no Binsex, "esquecendo" até de seus smartphones.

A partir das simulações, analisamos que o Binsex pode ser utilizado em dois momentos: como uma atividade lúdica e criativa introdutória aos conteúdos do livro didático de Biologia (citados anteriormente); ou como um instrumento de avaliação formativa. A atividade introdutória refere-se ao levantamento prévio dos conhecimentos dos/as estudantes sobre as temáticas, importante processo que contribui ao docente identificar objetivamente o conhecimento a ser trabalhado com a realidade dos/as estudantes, visando assim, um aprender efetivo e significativo.

Com vistas ao estímulo a uma reflexão crítica sobre uma vivência plena e consciente de cidadania, incluímos em quatro questões alguns termos que não estão contemplados no livro didático, mas que compreendemos como expressivos numa abordagem emancipatória de educação sexual: questão $\mathrm{n}^{0}$ 08: incluímos o termo 'prazer feminino' porque entendemos ser este um tema ainda tabu, inclusive visto e pensando unilateralmente na sociedade; questões $\mathrm{n}^{\circ}$ 23 e n n $^{\circ}$ 9: incluímos o termo 'planejamento familiar', porque de acordo com a Lei nº. 9.263/96 o planejamento familiar é um direito de todo cidadão; e na questão $\mathrm{n}^{\circ} 35$ : incluímos o termo 'consentimento', porque entendemos que toda e qualquer relação sexual entre pessoas precisa ser consentida. Compreendemos que estas três palavras podem contribuir para posteriores discussões junto aos estudantes, visando a reflexão crítica sobre atitudes e valores que envolvem prazer, direitos sexuais, saúde física e mental, abusos sexuais e cultura do estupro - temas tão polêmicos, mas necessários de intensa problematização, seja a nível local e/ou global, pois representam elementos fundamentais para a vivência da sexualidade de forma segura e saudável entre homens e/ou mulheres.

Durante as simulações também percebemos que a socialização de repostas foi um ato comum fraterno entre os/as participantes/estudantes. Aqueles/as que sabiam as respostas contribuíam em voz alta aos colegas com o intuito de facilitar a procura pelos termos em suas RIAEE - Revista Ibero-Americana de Estudos em Educação, Araraquara, v. 14, n. esp. 2, p. 1580-1600, jul., 2019. E-ISSN: 1982-5587. DOI: $10.21723 /$ riaee.v14iesp.2.12617 
cartelas. E assim que completavam a/s coluna/s ou cartela cheia, falavam em voz alta "BINGO!", recebendo ao final seu prêmio (brinde). Ressaltamos que, na intenção de não valorizar estritamente a competição, o/a docente também pode alterar as regas em algumas rodadas, premiando aquele/a estudante que faz "bingo" concomitantemente com aquele/a que não marcou nada - "cartela vazia", como também ocorre no jogo tradicional.

Referente ao papel docente, as avaliações das simulações demonstraram que o Binsex pode contribuir na relação comunicativa entre docentes e discentes. Todavia, conforme Tenreiro-Vieira e Vieira (2000), Yared, Vieira e Melo (2015) e Yared, Melo e Vieira (2015), para executar o Binsex, o/a docente precisa ter disposição para o diálogo, "abertura de espírito", coragem intelectual, reconhecer o direito dos/as estudantes ao conhecimento científico e à promoção da saúde sexual e reprodutiva, compromisso com orientações recomendadas pelos documentos orientadores e curriculares e humildade intelectual - postura de aprendiz e instrutor. Estas são habilidades e disposições de pensamento crítico que podem ser gradualmente estimuladas quando o/a docente se permite vivenciar estes processos. E a credibilidade e confiança podem ser gradualmente alcançadas a partir da dedicação e do estudo constante, visando o autoconhecimento e a ressignificação de si, dos outros e de sua visão de mundo - movimento este vivido e refletido criticamente pela primeira autora durante todo seu curso de mestrado sob orientação da segunda autora.

Por fim, mesmo com avaliações positivas pelos/as participantes das simulações, registramos que o jogo em si não promoveu argumentações durante sua execução. Debates, reflexões e indagações ocorreram posteriormente ao jogo, cabendo ao docente incentivar esse processo. Necessariamente, o Binsex também não representa uma estratégia didática a ser usada isoladamente, mas como uma metodologia em potencial incorporada ao planejamento do/a docente, visando trabalhar estes conteúdos de maneira lúdica, superando a aula expositiva.

\section{Considerações}

O Binsex representa uma proposta didático-metodológica lúdica que objetiva contribuir no processo de ensino-aprendizagem em educação sexual, bem como promover e assegurar o acesso à informação e ao conhecimento científico sobre sexualidade e saúde sexual enquanto direito aos estudantes da educação básica. Reiteramos que a informação correta é base fundamental para que cidadãos e cidadãs possam exercitar seu pensamento crítico e reflexivo 
- analisando, questionando e interpretando questões da vida cotidiana na vivência da sexualidade.

A partir da trajetória empírica da construção do jogo e das simulações iniciais desenvolvidas, compreendemos que é possível o Binsex promover o acesso à informação e ao conhecimento científico sobre sexualidade e saúde sexual de maneira mais ativa, reflexiva e lúdica. Registramos que o jogo se apresenta como um recurso metodológico alternativo para problematizar conteúdos de educação sexual presente nos livros didáticos de Ciências Biológicas, amenizando o "impacto" e "expectativa" de uma "aula de educação sexual" e, assim, encorajar docentes a trabalhar intencionalmente a temática, pautados conscientemente no paradigma emancipatório de sujeitos.

Registramos, inclusive, que o Binsex pode ser um instrumento promotor da (auto)reflexão docente, pois na sua interação, professores e professoras de Ciências Biológicas poderão refletir criticamente sobre suas práticas pedagógicas e seus conhecimentos sobre sexualidade e educação sexual. Esse movimento de autoavaliação pode contribuir na promoção do pensamento crítico nos ambientes escolares. Almejamos que o Binsex estimule outros/as docentes na inovação metodológica, na criação de dinâmicas e instrumentos didáticospedagógicos em educação sexual, algo que se faz urgente e necessário para potencializar o processo de ensino-aprendizagem dialógico e crítico nas aulas de Ciências e/ou Biologia que envolvam as temáticas da sexualidade e saúde sexual.

Por fim, ressaltamos a importância e necessidade de aprimoramento do jogo Binsex por meio de mais pesquisas e aprofundamento teórico. Novos estudos podem contribuir para aperfeiçoar essa estratégia didático-pedagógica para uma efetiva promoção do pensamento crítico-reflexivo, garantindo o direito ao acesso à informação e à educação sexual compreensiva, além de possíveis contribuições na formação inicial e continuada de docentes, no que tange ao estímulo de mudanças paradigmáticas no ensino de Ciências e Biologia.

AGRADECIMENTOS: Programa de bolsas Universitárias do estado de Santa Catarina (UNIEDU). 


\section{REFERÊNCIAS}

AÇÃO EDUCATIVA. A ideologia do movimento Escola Sem Partido: 20 autores desmontam o discurso/Ação Educativa, Pesquisa e Informação (Org.). - São Paulo: Ação Educativa, 2016.

BRASIL. Projeto de Lei $\mathbf{n}^{\mathbf{}} \mathbf{.} 867$ de 23 de março de 2015. Inclui, entre as diretrizes e bases da educação nacional, o "Programa Escola sem Partido". Disponível em:

https://www.camara.leg.br/proposicoesWeb/fichadetramitacao?idProposicao=1050668.

BRASIL, PCN - Parâmetros Curriculares Nacionais. 5a a 8a séries: Matemática. Brasília: MEC/SEF, 1997.

BRASIL, PCN - Parâmetros Curriculares Nacionais. 5a a 8a séries: Orientação Sexual. Brasília: MEC/SEF, 1997.

CABRAL, Juçara Teresinha. A sexualidade no mundo ocidental. Campinas, São Paulo: Papirus, 1995.

ENNIS, Robert H. The nature of critical thinking: an outline of critical thinking dispositions and abilities. This is a several-times-revised version of a presentation at the Sixth International Conference on Thinking at MIT, Cambridge, july, 1994. Last revised may, 2011. Disponível em:

http://faculty.education.illinois.edu/rhennis/documents/TheNatureofCriticalThinking_51711_ 000.pdf. Acesso em: 20 jun. 2016.

FRANCO, Amanda; VIEIRA, Rui Marques; SAIZ, Carlos. Pensamento crítico: as mudanças necessárias no contexto universitário. Revista de Estudios e Investigación en Psicología y Educación, vol. extr., nº. 07, 2017. DOI: https://doi.org/10.17979/reipe.2017.0.07.2233.

FREIRE, Paulo. Pedagogia do oprimido. 29a . Ed. Rio de Janeiro, Paz e Terra, 2005.

GARCIA, Paulo Sérgio; BIZZO, Nélio. A pesquisa em livros didáticos de ciências e as inovações no ensino. Educação em Foco. v. 13, n. 15, 2010.

KNEUBIL, Fabiana Botelho; PIETROCOLA, Maurício. A pesquisa baseada em design: visão geral e contribuições para o ensino de ciências. In: Investigações em Ensino de Ciências. V. 22 (2) - Ago, 2017.

MATTOS, Amana et al. Educação e liberdade: apontamentos para um bom combate ao Projeto de Lei Escola sem Partido. In: FRIGOTTO, Gaudêncio (Org.). Escola "sem" partido: esfinge que ameaça a educação e a sociedade brasileira. Rio de Janeiro: UERJ, LPP, 2017.

MELO, Sônia Maria Martins de. Corpos no espelho: a percepção da corporeidade em professoras. Campinas, SP: Mercado de Letras, 2004. (Coleção Dimensões da Sexualidade). 
MELO, Sônia Maria Martins de. Educação e sexualidade / Sônia Maria Martins de Melo et al.; design instrucional Carmen Maria Cipriani Pandini - 2.ed. rev. - Florianópolis:

UDESC/CEAD/UAB, 2011.

MELO, Sonia Maria Martins de; POCOVI, Rosi. Educação e Sexualidade. $2^{\text {a }}$ Ed. Caderno Pedagógico, v.1, Florianópolis: UDESC, 2008.

NUNES, Cesar Aparecido. Desvendando a sexualidade. 7. ed. Campinas, SP: Papirus, 2005.

NUNES, Cesar Aparecido. Filosofia, sexualidade e educação: as relações entre os pressupostos ético-sociais e histórico-culturais presentes nas abordagens institucionais sobre a educação sexual escolar. 1996. 319f. Tese (Doutorado) - Faculdade de Educação, Universidade Estadual de Campinas, Campinas, 1996.

OMS. (1975). Organização Mundial da Saúde. Disponível em:

http://www.who.int/countries/bra/en/

SANTA CATARINA, Governo do Estado. Secretaria do Estado da Educação. Proposta Curricular de Santa Catarina/ Estado de Santa Catarina, 192 p., 2014.

SANTOMÉ, Jurjo Torres. O curriculum oculto. Portugal, Porto Editora, 1995.

SANTOS, Claudiene; BRUNS, Maria Alves de Toledo. A educação sexual pede espaço: novos horizontes para a práxis pedagógica. São Paulo: Ômega Editora, 2000.

SILVA, Tomaz Tadeu da. Documentos de identidade: uma introdução às teorias do currículo. - 3. Ed. - 1. Reimp - Belo Horizonte: Autêntica, 2005.

TENREIRO-VIEIRA, Celina. Perspectivas futuras de investigação e formação sobre pensamento crítico: potenciais convergências com as literacias Científica e Matemática. In: VIEIRA, Rui Marques; TENREIRO-VIEIRA, Celina; SÁ-CHAVES, Idália; MACHADO, Celeste. (Org.) Pensamento Crítico na Educação: perspectivas atuais no panorama internacional. Aveiro: UA Editora, 2014.

TENREIRO-VIEIRA, Celina. Investigação sobre o pensamento crítico na educação: contributos para a didática das Ciências. In: VIEIRA, Rui Marques et al. (Org.). Perspectivas futuras de investigação sobre pensamento crítico: potenciais convergências com as literacias científica e matemática. Aveiro: UA Editora, p, 29-39, 2014.

TENREIRO-VIEIRA, Celina; VIEIRA, Rui Marques. Promover o pensamento crítico dos alunos: propostas concretas para a sala de aula. Porto/Portugal: Porto Editora, 2000.

VIEIRA, Rui Marques; VIEIRA, Celina. Estratégias de ensino/aprendizagem: o questionamento promotor do pensamento crítico. Coleção: Horizontes pedagógicos, sob a direção de António Oliveira Cruz. Instituto Piaget: Lisboa, 2005.

YARED, Yalin Brizola. A educação sexual na escola: Tensões e prazeres na prática pedagógica de professores de Ciências e Biologia. 2011. 140f. Dissertação (Mestrado) Programa de Mestrado em Educação, Universidade do Planalto Catarinense, Lages, 2011. 
YARED, Yalin Brizola. Do prescrito ao vivido: a compreensão de docentes sobre o processo de educação sexual em uma experiência de currículo integrado de um curso de Medicina. 2016.

YARED, Yalin Brizola; MELO, Sónia Maria Martins de; VIEIRA, Rui Marques. Relevância do pensamento crítico para a educação sexual intencional emancipatória. In: DOMINGUEZ, Caroline, (Coord. Ed.) Pensamento crítico na educação: desafios atuais. Vila Real: UTAD, p. 233-239, 2015. Disponível em:

https://repositorio.utad.pt/bitstream/10348/4818/3/Pensamento\%20Cr\%C3\%ADtico\%20na\%2 0Educa\%C3\%A7\%C3\%A3o\%20-\%20Desafios\%20Atuais\%20\%5B2015\%5D.pdf. Acesso em: 20 jun. 2016.

WAS - Associação Mundial pela Saúde Sexual. Declaração dos direitos sexuais. 2014.

Disponível em: http://www.worldsexology.org/wp-content/uploads/2013/08/DSR-

Portugese.pdf.

\section{Como referenciar este artigo}

SILVA, Ediane; YARED, Yalin Brizola. Binsex: uma proposta de bingo como recurso didático em abordagem criticada educação sexual. Revista Ibero-Americana de Estudos em Educação, Araraquara, v. 14, n. esp. 2, p. 1580-1600, jul., 2019. E-ISSN: 1982-5587. DOI: 10.21723/riaee.v14iesp.2.12617

Submetido em: 30/09/2018

Revisões requeridas: 10/03/2019

Aprovado em: 27/05/2019

Publicado em: 25/06/2019 


\section{ANEXOS}

\section{Anexo 1}

Quadro 1 - Modelo cartelas Binsex - 1 cartela mestre e 4 cartelas série

\begin{tabular}{|c|c|c|c|c|}
\hline \multicolumn{5}{|l|}{ BINSEX } \\
\hline B & I & $\mathrm{N}$ & $\mathrm{G}$ & $\mathrm{O}$ \\
\hline & LAQUEADURA & HERPES & HIV & \\
\hline CAMISINHA & ESPERMICIDA & & $\begin{array}{l}\text { ANEL } \\
\text { VAGINAL }\end{array}$ & BEIJAR \\
\hline VASECTOMIA & $\begin{array}{l}\text { PERÍODO } \\
\text { FÉRTIL }\end{array}$ & HÍMEM & POLUÇÃO & ACNE \\
\hline DIA FÉRTIL & & ABRAÇAR & & PREPÚCIO \\
\hline
\end{tabular}
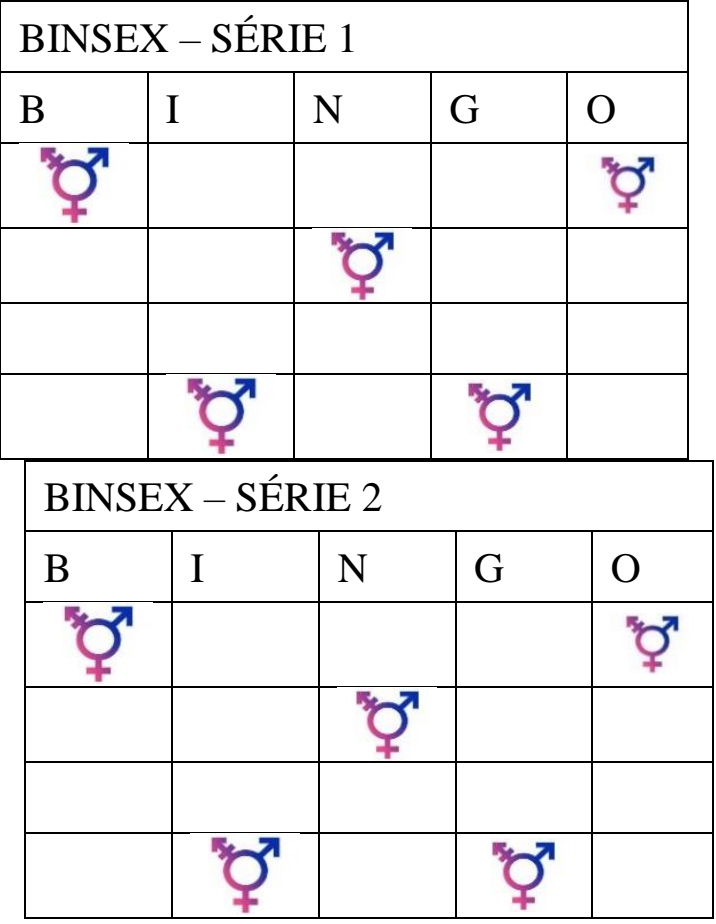

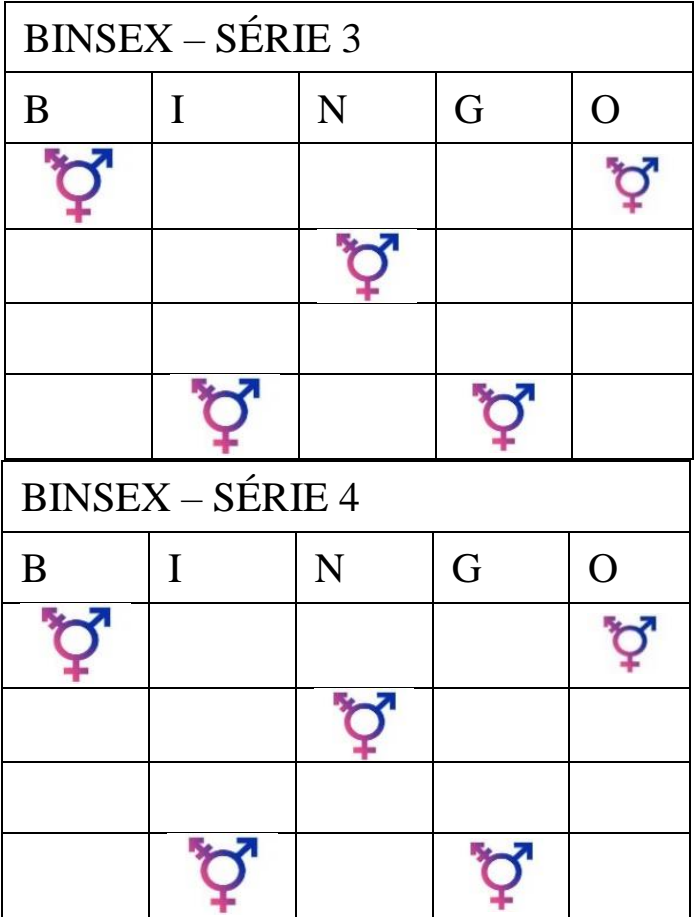

Fonte: Elaboração própria com última alteração em 2018/01. 


\section{Anexo 2}

Quadro 2 - Lista de questões numeradas de 01 a 39

\begin{tabular}{|c|c|c|}
\hline $\mathrm{N}^{\mathrm{o}}$ & Questão & Palavra \\
\hline 1. & $\begin{array}{l}\text { Que ação exercida pelos braços mantém duas ou mais pessoas } \\
\text { unidas? }\end{array}$ & Abraçar \\
\hline 2. & $\begin{array}{l}\text { O acúmulo de glândulas sebáceas, que servem de alimentos para } \\
\text { as bactérias, pode produzir que tipo de estrutura na pele dos/as } \\
\text { adolescentes? }\end{array}$ & Acne \\
\hline 3. & $\begin{array}{l}\text { Que objeto, plástico e flexível, é inserido na vagina para atuar } \\
\text { como contraceptivo? }\end{array}$ & Anel Vaginal \\
\hline 4. & $\begin{array}{l}\text { Método utilizado para prevenir a gravidez após uma relação } \\
\text { sexual desprotegida que pode ser usado em até } 72 \mathrm{~h} \text { ? }\end{array}$ & $\begin{array}{l}\text { Anticoncepcional de } \\
\text { emergência }\end{array}$ \\
\hline 5. & $\begin{array}{l}\text { Também considerado um gesto de afeição, que ação representa } \\
\text { a aproximação dos lábios em uma pessoa ou em objetos? }\end{array}$ & Beijar \\
\hline 6. & $\begin{array}{l}\text { Objeto em formato de bolsa com dois anéis flexíveis, onde o anel } \\
\text { menor é inserido dentro do canal vaginal e o outro, maior, ficará } \\
\text { externamente cobrindo os pequenos e grandes lábios. }\end{array}$ & Camisinha feminina \\
\hline 7. & $\begin{array}{l}\text { Envoltório fino de látex que cobre o pênis durante a relação } \\
\text { sexual. }\end{array}$ & Camisinha masculina \\
\hline 8. & $\begin{array}{l}\text { Órgão localizado na parte superior da vulva, de grande } \\
\text { importância para o prazer feminino, constituído de tecido erétil, } \\
\text { assim como o pênis, que durante a excitação pode alongar e } \\
\text { mudar de tamanho. }\end{array}$ & Clitóris \\
\hline 9. & O $14^{\circ}$ dia após o início da menstruação é considerado o dia...? & Dia fértil \\
\hline 10. & $\begin{array}{l}\text { Quando há uma exteriorização do esperma, dizemos que há } \\
\text { uma...? }\end{array}$ & Ejaculação \\
\hline 11. & $\begin{array}{l}\text { Qual nome do duto microscópico por onde atravessam os } \\
\text { espermatozoides? }\end{array}$ & Epidídimo \\
\hline 12. & $\begin{array}{l}\text { Qual célula masculina se movimento por flagelo e carrega } \\
\text { metade das informações genéticas? }\end{array}$ & Espermatozoide \\
\hline 13. & Substância química que pode matar os espermatozoides. & Espermicida \\
\hline 14. & $\begin{array}{l}\text { Hormônio produzido pelos ovários e liberado na primeira fase } \\
\text { do ciclo menstrual. }\end{array}$ & Estrogênio \\
\hline 15. & $\begin{array}{l}\text { Condição em que o prepúcio, apertado, não pode ser puxado para } \\
\text { expor a glande do pênis. }\end{array}$ & Fimose \\
\hline 16. & $\begin{array}{l}\text { Resultado da fecundação de um óvulo pelo espermatozoide, que } \\
\text { envolve o subsequente desenvolvimento intrauterino do feto, até } \\
\text { sua expulsão. }\end{array}$ & Gravidez \\
\hline 17. & $\begin{array}{l}\text { Qual a infecção sexualmente transmissível que causa irritação e } \\
\text { inflamação no fígado? }\end{array}$ & Hepatite B \\
\hline 18. & $\begin{array}{l}\text { Infecção transmitida por contato com a pele e pode ter } \\
\text { manifestação bucal ou genital. }\end{array}$ & Herpes \\
\hline 19. & $\begin{array}{l}\text { Membrana mucosa que fecha parcialmente o orifício externo da } \\
\text { vagina e que, geralmente, é rompido durante a } 1^{\text {a }} \text { relação sexual. }\end{array}$ & Hímen \\
\hline 20. & Qual é o vírus causador da AIDS? & HIV \\
\hline
\end{tabular}




\begin{tabular}{|c|c|c|}
\hline 21. & $\begin{array}{l}\text { Qual vírus apresenta mais de } 150 \text { tipos, atinge a pele e as } \\
\text { mucosas podendo causar verrugas percussoras de câncer de colo } \\
\text { de útero, garganta ou ânus? }\end{array}$ & HPV \\
\hline 22. & Sigla de “infecções sexualmente transmissíveis". & IST \\
\hline 23. & $\begin{array}{l}\text { Procedimento médico que trata do planejamento familiar e que } \\
\text { permite a esterilização em mulheres que têm certeza que não } \\
\text { desejam uma gravidez futura. }\end{array}$ & Laqueadura \\
\hline 24. & Fluxos de sangue eliminados periodicamente pela vagina. & Menstruação \\
\hline 25. & Órgão onde são produzidos os gametas femininos. & Ovário \\
\hline 26. & Qual a célula de reprodução feminina? & Óvulo \\
\hline 27. & Nome dos apêndices filiformes e coniformes da pele. & Pelos \\
\hline 28. & Órgão sexual masculino. & Pênis \\
\hline 29. & $\begin{array}{l}\text { Período com durabilidade de } 7 \text { dias e com alta probabilidade de } \\
\text { gerar uma gestação quando acontece a relação sexual } \\
\text { desprotegida. }\end{array}$ & Período fértil \\
\hline 30. & $\begin{array}{l}\text { Comprimido que contém hormônios sintéticos parecidos com os } \\
\text { que as mulheres produzem. }\end{array}$ & Pílula anticoncepcional \\
\hline 31. & $\begin{array}{l}\text { Ejaculação involuntária que ocorre durante o sono, muito } \\
\text { comum entre os } 12 \text { e } 20 \text { anos de idade. }\end{array}$ & Polução noturna \\
\hline 32. & Prega cutânea que recobre a glande do pênis? & Prepúcio \\
\hline 33. & $\begin{array}{l}\text { Qual o hormônio sexual esteroide essencial para o equilíbrio do } \\
\text { ciclo ovariano e para a gerar gravidez? }\end{array}$ & Progesterona \\
\hline 34. & $\begin{array}{l}\text { Qual glândula exócrina que faz parte do sistema genital } \\
\text { masculino, produz e armazena um fluido incolor e ligeiramente } \\
\text { alcalino? }\end{array}$ & Próstata \\
\hline 35. & $\begin{array}{l}\text { Qualquer aproximação íntima consentida que envolva os órgãos } \\
\text { sexuais das pessoas (pênis, vulva), inclusive boca e ânus. }\end{array}$ & Relação sexual \\
\hline 36. & Qual o hormônio masculino produzido nos testículos? & Testosterona \\
\hline 37. & $\begin{array}{l}\text { Órgão muscular oco do aparelho genital feminino que acolhe o } \\
\text { ovo fecundado durante seu desenvolvimento e o expulsa, ao final } \\
\text { da gestação. }\end{array}$ & Útero \\
\hline 38. & $\begin{array}{l}\text { Estrutura anatômica tubular que vai do útero até o orifício } \\
\text { externo do canal genital feminino. }\end{array}$ & Vagina \\
\hline 39. & $\begin{array}{l}\text { Procedimento médico que trata do planejamento familiar e que } \\
\text { permite a esterilização em homens que têm certeza que não } \\
\text { desejam uma gravidez futura. }\end{array}$ & Vasectomia \\
\hline
\end{tabular}

Fonte: Elaboração própria. 